\title{
Indicators for assessing sustainability of power plants: environmental, social, economic and technical aspects
}

\author{
J.J. Cartelle ${ }^{1}$, M. Lara ${ }^{1}$, M.P. de la Cruz ${ }^{1}$ and A. del Caño ${ }^{1}$ \\ ${ }^{1}$ Departamento de Ingeniería Industrial II \\ Escuela Politécnica Superior, Universidade da Coruña \\ Campus de Esteiro, 15403 Ferrol (Spain)
}

Phone/Fax number: +0034 981 337400, e-mail: juan.cartelle1@udc.es, m.lara@udc.es, pcruz@udc.es, alfredo@udc.es

\begin{abstract}
The public is increasingly aware of the problems caused by unbridled development. More and more, governments, companies and other organisations are establishing sustainable development policies for making more likely that future generations can satisfy their own needs.
\end{abstract}

A set of environmental, social, economic and technical-functional indicators are proposed and described here. These indicators are useful to create complete models for assessing the global sustainability of renewable and non-renewable power plants throughout their life cycles.

This set of indicators can be useful for engineers, researchers and, in general, decision makers in the energy policy field. This is the first step to achieve more sustainable energy mixes.

\section{Key words}

Global sustainability, power plants, sustainability indicators, Life-Cycle Analysis.

\section{Introduction}

Since the last quarter of the XX century, many authors have coincided: neither the Earth's ecosystems nor the world populations and their communities will be capable to withstand the impact made by human activity, if the present growing dynamic is maintained over the years. Therefore, it is currently accepted that there are limits to growth [1].

Some specific terms and concepts have come to the forefront in almost every sector of activity, including, among others, the economy, industry, energy and construction. Terms that stand out in this new vocabulary are sustainable development and integral sustainability.

Sustainable development can be defined in various ways, depending on the analytical standpoint. The most common accepted guidelines were introduced by the United Nations in 1987 (Brundtland Report), and extended in 1992 by the Rio Declaration on Environment and Development [2]. According to these documents, development is deemed sustainable when it satisfies present needs without compromising the capacity of future generations to satisfy their own needs. Moreover, integral or global sustainability goes beyond purely environmental aspects; social and economic factors, as well as ethical and cultural concerns, come into play.

On the other hand, a modern society needs an energy system that ensures a constant supply. At the heart of this system there shall be abundant resources, obtained at a reasonable cost and easily transported. These resources must also be of an adequate quality, suitable for machines and equipment.

Throughout its history, mankind has used two crucial criteria when choosing energy systems: technical availability and economic viability. It is only in the last few decades that other criteria for this decision have been taken into account: the environmental and social impacts that a system may have. These new factors already play a key role when they come to assessing and comparing different energy systems.

There are different methods for assessing the sustainability of products and processes. Frequently sustainability assessment is done by performing life-cycle analysis (LCA). Conventional LCA is a technique to assess environmental impacts associated with all the stages of a product's life-cycle, from cradle to grave. It is based on assessing different environmental indicators. An indicator is a variable employed for measuring a specific impact on the planet. The use of LCA has been extended to the economic and social fields. The results of LCA can be used directly, but there are methods for integrating the different indicators' assessments.

The majority of integration methods currently used in the construction sector are based on a weighted scoring system for different sustainability indicators. Research is being done at the moment on more sophisticated alternatives, such as the analytic hierarchy process 
(AHP), the MIVES method (Integrated Value Method for Evaluating Sustainability), or fuzzy mathematics.

Sustainable development can be considered a recent discipline within the energy sector. Nevertheless, it has already caught the attention of a number of authors and organizations and some assessment models have been produced. For instance, Begic' and Afgan [3] offered a multi-criteria analysis model based on the ASPID (Analysis and Synthesis of Parameters under Information Deficiency) method for the evaluation of the sustainability of eight energy systems in Bosnia-Herzegovina. Kahraman et al. [4] applied two fuzzy Multi-criteria Decision Making (MCDM) methodologies for the selection among renewable alternatives for Turkey, by considering technological, environmental, social and economic indicators. In [5], the authors examined ten renewable technologies of power generation in a multi-criteria sustainability assessment frame of seven attributes. Existing models cannot be considered adequate or complete due to any of the following reasons: they are based on a method that does not capture the complexity of the problem, they do not treat in depth all the pillars of sustainability, particularly, the social one; they do not consider certain key indicators. To this end, authors are working to create a comprehensive model for assessing the global sustainability of power plants throughout their life cycles (Fig. 1). To create the model authors will apply the MIVES method [6].

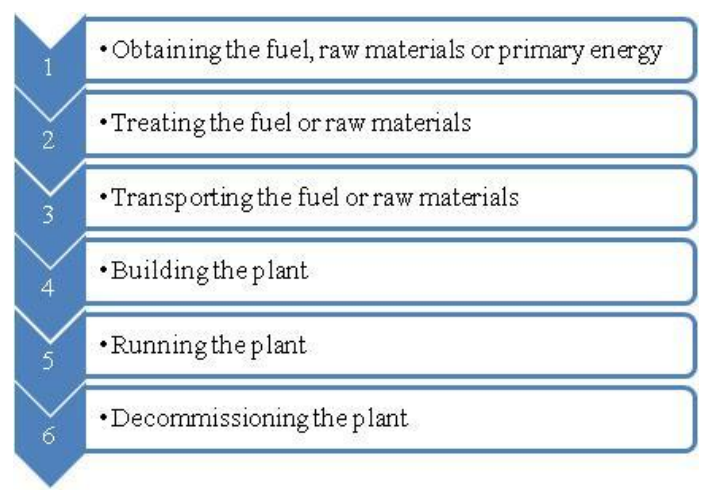

Fig. 1. Life cycle stages considered in the study.

This model will make it possible to compare the main renewable and non-renewable energy systems according to integral sustainability criteria. It may be used to support decision making, which would lead to a more sustainable energy mix.

The aim of this paper is to present the set of environmental, social, economic and technical-functional indicators that the authors are considering to employ in the assessment model. The indicators have been selected from an extensive literature review including [3][4][5][7][8][9] and [10], among many others.

\section{Environmental indicators}

Below there is a proposal for a very complete set of environmental indicators, together with a short description of each one. The units of measurement are also specified. Indicators M4 and M15 to M19 have no measurement units because they will be evaluated in a qualitative manner through semantic labels. For example, one possibility is to use five semantic labels: very low, low, medium, high and very high. Each label will be associated with a level of satisfaction between 0 and 1, being the unit the greatest contribution to sustainable development. A panel of experts can be used to associate one of the five semantic labels to each type of power plant. There are other options that can be appropriate, depending on the case.

Global warming (M1). It is the observed century-scale rise in the average temperature of Earth's climate system. With current patterns of generation and consumption, the increase of the temperature could reach $0.3{ }^{\circ} \mathrm{C}$ per decade. This indicator is measured in kilograms $(\mathrm{kg})$ of equivalent carbon dioxide emissions per terajoule (TJ) of energy produced.

Depletion of the ozone layer (M2). The ozone layer protects from harmful effects of solar radiation to all living beings on the planet. Chlorofluorocarbon (CFC) emissions, among other substances, contribute to the depletion of the ozone layer. This environmental impact is measured in $\mathrm{kg}$ of equivalent trichlorofluoromethane (CFC-11) emissions per TJ of energy produced.

Acidification (M3). It can be defined as the loss of the neutralizing capacity of the soil and water. This is a consequence of atmospheric emissions of acidifying substances such as sulphur dioxide $\left(\mathrm{SO}_{2}\right)$ and nitrogen oxides $\left(\mathrm{NO}_{\mathrm{x}}\right)$. These substances can persist in the air for up to a few days and thus can be transported over thousands of kilometres, when they undergo chemical conversion into sulphuric and nitric acids. The acidification is measured in $\mathrm{kg}$ of equivalent $\mathrm{SO}_{2}$ emissions per TJ of energy produced.

Ionizing radiation (M4). It is radiation that carries enough energy to strip electrons from atoms and to break chemical bonds, which creates highly reactive ions.

Eutrophication (M5). This phenomenon is a type of chemical water pollution caused by an excessive supply of artificial and natural substances, mainly phosphates and nitrates, to an aquatic ecosystem. Eutrophication leads to ecosystems with reduced biodiversity. This indicator is measured in $\mathrm{kg}$ of equivalent phosphate $\left(\mathrm{PO}_{4}{ }^{3-}\right)$ emissions per $\mathrm{TJ}$ of energy produced.

Heavy metals (M6). Any metal or metalloid of environmental concern is a heavy metal. Commonly encountered heavy metals are chromium $(\mathrm{Cr})$, cobalt $(\mathrm{Co})$, nickel $(\mathrm{Ni})$, copper $(\mathrm{Cu})$, zinc $(\mathrm{Zn})$, arsenic (As), selenium (Se), silver (Ag), cadmium (Cd), antimony $(\mathrm{Sb})$, mercury $(\mathrm{Hg})$, thallium $(\mathrm{Tl})$ and lead $(\mathrm{Pb})$. Heavy metals cannot be degraded and also tend to bioaccumulate and biomagnify causing different types of toxic effects. In humans were detected myriad of physical and psychological effects. This impact is measured in $\mathrm{kg}$ of equivalent $\mathrm{Pb}$ emissions per $\mathrm{TJ}$ of energy produced. 
Carcinogens (M7). Any substance, radionuclide or radiation that is an agent directly involved in causing cancer can be considered a carcinogen. Some of the most common carcinogens are $\mathrm{As}, \mathrm{Ni}$, benzene $\left(\mathrm{C}_{6} \mathrm{H}_{6}\right)$, fluorine $(\mathrm{F})$, ethylbenzene $\left(\mathrm{C}_{8} \mathrm{H}_{10}\right)$, and polycyclic aromatic hydrocarbons (PAH). This environmental impact is measured in $\mathrm{kg}$ of $\mathrm{PAH}$ emissions per $\mathrm{TJ}$ of energy produced.

Winter smog (M8). The winter smog is the one caused by a high concentration of suspended particles and $\mathrm{SO}_{2}$ in the air. These substances act as condensation nuclei of the steam under conditions of high humidity and low temperatures. This impact is measured in $\mathrm{kg}$ of equivalent $\mathrm{SO}_{2}$ emissions per TJ of energy produced.

Summer smog (M9). It is the chemical reaction of sunlight and the primary pollutants (nitrogen oxides $\left(\mathrm{NO}_{\mathrm{x}}\right)$ and volatile organic compounds (VOC) in the atmosphere, which produces a mixture of different and hazardous chemicals known as secondary pollutants. All of these chemicals are usually highly reactive and oxidizing. This indicator is measured in $\mathrm{kg}$ of equivalent ethene (ethylene; $\mathrm{C}_{2} \mathrm{H}_{4}$ ) emissions per TJ of energy produced.

Conventional waste generation (M10). Waste generation entails logistical, treatment, disposal and monitoring problems, with a large number of economic, social and environmental implications. In the longer term, there are implications associated with the depletion of raw materials and resources. Reusing, recycling and valorisation processes are the global solution to this problem. This indicator measures the amount of waste deposited in conventional landfills. The units of measurement are $\mathrm{kg}$ of conventional waste per TJ of energy produced.

Special waste generation (M11). It measures the amount of waste deposited in special landfills. The units of measurement are $\mathrm{kg}$ of special waste per TJ of energy produced.

High-level waste generation (M12). It includes alpha emitting materials, beta or gamma emitting materials that exceed the radioactive level of the intermediate level waste, and those materials with a half life greater than 30 years. This indicator is measured in $\mathrm{kg}$ of high-level waste per TJ or energy produced.

Intermediate-level and low-level waste generation (M13). It includes beta or gamma emitting materials with an intermediate or low radioactive level, and those materials with a half life less than 30 years. The units of measurement are $\mathrm{kg}$ of intermediate-level and low level waste per TJ of energy produced.

Sterile waste generation (M14). Sterile waste with a radioactive level that is not dangerous both for human health and the environment. The units of measurement are $\mathrm{kg}$ of sterile waste per TJ of energy produced.

Available reserves of fuel and raw materials (M15). Nonrenewable energy resources are limited (fossil fuels and minerals).
Land use (M16). Power plants may occupy vast tracts of land that could be used for other purposes, which implies the existence of a marginal cost in land use. As mentioned above, this indicator can be assessed in a qualitative way. However, this impact can also be measured in square kilometers per megawatt (MW) of installed power [7][8], or in hectares per kilowatts hour $(\mathrm{kWh})$ of energy produced [5].

Noise (M17). Noise generated during the life cycle under consideration.

Bad odours (M18). Unpleasant odours generated during the life cycle under consideration.

Impact geographical range (M19). Evaluates how easy it is to adopt safeguards and reforms in response to the environmental impact caused.

The reader can find more information for the indicators M1 to M15 in [11]. The studies [4][5][7][8][10] provide information for the indicator M16, as well as in [9] the reader can find information for the indicator M17.

\section{Social indicators}

Following there is a description of the social indicators considered. The units of measurement are established for indicator $\mathrm{S} 1$, since indicators $\mathrm{S} 2$ to $\mathrm{S} 9$ have no measurement units, because they are qualitative variables assessed in the same way that the ones in the environmental field.

Employment generation (S1). This indicator considers the direct and indirect employment generated during the life cycle under consideration. The units of measurement are workers per MW of installed power.

Population displacement (S2). An electric power plant can be built in an uninhabited or sparsely populated area, which then grows in population, or the opposite effect may happen.

Social benefits (S3). It measures the possibility of setting up a plant in zones far from highly industrialised areas. This helps assess the economic boost for less developed areas, decentralising energy production and resulting in equality and development. This indicator also includes the benefits derived from the construction of schools, sports centres and other infrastructures financed by the electrical company.

Risk of construction accidents (S4). It includes accidents of any type during the construction of the power plant.

Risk of operation and maintenance accidents (S5). Accidents of any type during the operation and maintenance of the power plant.

Risk of external accidents (S6). This indicator includes the rest of possible accidents that are not considered in the indicators S4 and S5. 
Visual impact (S7). It evaluates the aesthetics of the energy system's installations, and the visual pollution that harms the environment that surrounds it.

Social acceptability (S8). It collects the opinion of the lay public about each type of energy system. Its aim is to assess the social opposition to each power plant. There is a relationship between this indicator and the NIMBY concept (Not In My Back Yard).

Effect on public budget (S9). Some energy systems enjoy financial advantages such as premiums, special rates, bonus for special regimes of electricity production, investment aids, among others. These advantages have a repercussion on the public budget. They also have a social repercussion because the money could be put toward dependency, education, etc.

Quantifying the social dimension of sustainability is a difficult task [12]. Nevertheless, some useful information for this study has been produced. Information concerning the employment generation in conventional power plants is provided in [12][13]. On the other hand, [14] provides the employment generated in renewable power plants. In [5][15] the reader can find information about the indicator S3. There are documents providing information related to the risk of accident and security aspects [16][17]. As for visual impact, wind power is the most studied so far [18]. Regarding the indicator S8, Raven et al. [19] present a general approach for managing the social acceptance of new energy projects. Kaldellis et al. [20] made a study about the social acceptability of the wind power. On the other hand, [9] provides information about the effect on public spending, that is the indicator $\mathrm{S} 9$.

\section{Economic indicators}

A proposal for a set of economic indicators is now suggested, including the opportune units of measurement.

Mining and extraction cost (E1). It includes equipment, machinery, accessories and labour needed to extract the raw material or fuel used. The measurement units are euros $(€)$ per TJ of energy produced.

Pre-treatment and enrichment cost (E2). The process of washing, milling, drying, refining, distilling, enriching, eliminating impurities and other processes needed to burn the fuel in the plant are under consideration. This indicator is measured in $€$ per TJ of energy produced.

Transportation cost (E3). This is the cost of transporting the raw material or fuel from the extraction point to the plant. It is measured in $€$ per TJ of energy produced.

Engineering cost (E4). It includes designing the plant and, generally, all the necessary infrastructures and buildings. The measurement units are $€$ per TJ of energy produced. E4 is the product of dividing the total cost of the engineering activities by the number of TJ generated over the working life of the power plant, which can be different from one type to another.
Process equipment cost (E5). It includes boilers, alternators, control and monitoring systems, turbines, wind turbines, condensers, nuclear reactors, solar panels, pipe work, steam generators and, generally, all of the necessary equipment for the plant to run well. This indicator is measured in $€$ per TJ of energy produced (total cost divided by the working life of the plant).

Cost of civil works (E6). Costs related to land acquisition, earthmoving, excavating and erecting all the buildings and necessary infrastructures are included. It is measured in $€$ per TJ of energy produced (total cost divided by the working life of the plant).

Cost of fuel and $\mathrm{CO}_{2}$ emission rights (E7). It includes the cost of buying the fuel (from which E1, E2 and E3 will be deducted, when it is appropriate), and cost of buying $\mathrm{CO}_{2}$ emission rights. The units of measurement are $€$ per $\mathrm{TJ}$ of energy produced.

Operation and maintenance cost (E8). This indicator includes fixed and variable costs, measured in $€$ per TJ of energy produced.

Decommissioning cost (E9). This indicator includes the cost of equipment decommissioning, civil works demolition, removing equipment and materials, cleaning and restoring the affected areas, and tracking the restoration measures. It is measured in $€$ per TJ of energy produced (total cost divided by the working life of the plant).

Subsidies (E10). This indicator may include all the financial advantages that a power plant can have. One possibility, is to consider it like a state help in the initial investment. In this case, subsidies are measured in form of percentage of initial investment.

The economic pillar is one of the most studied, so there is a lot of information available on it. For example, [21][22][23] gives information about E1. The indicator E2 is treated in [23]. In [21][22][23], the reader can find data about the transportation costs. The indicators E4, E5 and E6 are considered in [14][24][25]. Moreover, some studies provide fuel costs [21][23][26][27]. In [14][26][27], information about E8 is provided; and finally the dismantling of certain types of power plants are addressed in [28][29].

\section{Technical-functional indicators}

Finally, a description of the technical-functional indicators is included below. These indicators have no measurement units because they are qualitative variables assessed in the same way that the previous qualitative ones.

Reliability of electricity supply (T1). Disruptions in energy production due to breakdowns, failures or problems during the energy supply are considered. Obviously, it is necessary to use alternative systems to satisfy the unmet demand by the unreliable ones. 
Variability / regularity of electricity supply (T2). Some energy systems depend on phenomena such as wind or solar radiation, among others; therefore they cannot produce energy at any time. This variability is a weak point because they cannot cover the entire energy demand.

Stability of the power supply chain (T3). The variability in the energy production causes instabilities (producing voltage drops and other problems) that are difficult to absorb by the electrical network.

Uncertainty in generation (T4). Although certain energy systems generate instabilities, not all of them have the same degree of uncertainty (for instance, the intensity of the solar radiation tends to change more gradually than the wind speed). This indicator measures the degree of uncertainty in the appearance of instabilities.

Generation manageability (T5). This indicator evaluates how easy is to adopt measures in response to the instabilities which are produced by certain power plants before being integrated into the electrical network.

Maturity (T6). Maturity is an important aspect in the energy planning in the medium and long term. It should be taken into account the possibility that new technologies become commercially viable. It is necessary to pay particular attention to their stages of development, the state in which they are at the time of the analysis and their future states (within the time horizon of the study). This indicator measures the degree of maturity of the technology used in each power plant.

Some authors have addressed the technological dimension, including indicators similar to those presented here. For instance, Diakoulaki and Karangelis [30] considered the amount of energy produced with $100 \%$ of certainty, the ability to respond to peak load, and the security of the system supply. In [9], the authors have analised the diversity of technologies, the technological advantages, and the security of supply.

\section{Quantitative data}

In this section, the minimum and maximum values are proposed for some of the indicators considered in this work. To this end, the following power plants have been taken into account: coal fired power plant $(\mathrm{C} 1)$, lignite thermal power plant (C2), oil-fired power plant (C3), natural gas fired power plant $(\mathrm{C} 4)$, nuclear power plant (C5), photovoltaic solar plant (R1), onshore wind farm (R2), offshore wind farm (R3), mini-hydroelectric power plant (R4), biomass power plant (R5), high temperature solar thermal power plant (R6), and high temperature solar thermal power plant hybridized with natural gas (R7). Table I shows the numerical values and, in brackets, the type of power plant that generates each value. The indicators are measured in the units previously defined. More than 80 publications (some already mentioned) have been consulted.

The minimum value for the indicators E1, E2, E3 and E7 has been established without taking into account the alternatives R1-R4 and R6-R7, which take values of zero or near zero. On the other hand, the sum of the indicators E4, E5 and E6 is the investment cost. In this case, the indicators E1, E2 and E3 were not deducted from E7. For decommissioning costs (E9), the alternatives R1, R5-R7 were not considered due to the lack of data and real cases. The authors are working in order to establish the corresponding values for the rest of the indicators. It is expected, that the majority of real case studies have values within the ranges indicated in Table I.

Table I. - Sustainability indicators in the energy sector

\begin{tabular}{|l|c|c|}
\hline \multicolumn{1}{|c|}{ Indicator } & Minimum & Maximum \\
\hline S1 & $0.4(\mathrm{C} 1, \mathrm{C} 2, \mathrm{C} 3)$ & $27(\mathrm{R} 5)$ \\
\hline E1 & $220(\mathrm{C} 5)$ & $16.800(\mathrm{R} 5)$ \\
\hline E2 & $150(\mathrm{C} 1)$ & $3.970(\mathrm{R} 5)$ \\
\hline E3 & $0(\mathrm{C} 2)^{1}$ & $9.020(\mathrm{C} 1)$ \\
\hline E4+E5+E6 & $460(\mathrm{C} 4)$ & $34.980(\mathrm{R} 6)$ \\
\hline E7 & $750(\mathrm{C} 5)$ & $27.270(\mathrm{C} 3)$ \\
\hline E8 & $610(\mathrm{C} 3)$ & $13.960(\mathrm{R} 3)$ \\
\hline E9 & $12(\mathrm{C} 3)$ & $5.500(\mathrm{R} 4)$ \\
\hline${ }^{1}$ It is considered that the mines are next to the lignite plants \\
\hline
\end{tabular}

\section{Conclusions}

This work presents a set of environmental, social, economic and technical-functional indicators selected from an extensive literature review. This collection of parameters is suitable for creating a comprehensive model for assessing the global sustainability of renewable and non-renewable power plants throughout their life cycles.

Assessing different energy systems would make it possible to compare various alternatives and produce a list that orders them according to their contribution to sustainable development. From it, information can be extracted that is valuable for power plant designers, energy planners and, in general, decision makers in the energy policy field. As a result, the model that contains the set of indicators proposed in this work can be useful for both energy sector professionals and those carrying out research in this field.

During the work for establishing the indicators, the main problem has been the identification of the most important ones that include all the possible circumstances that could happen, as well as the assessable aspects that could arise throughout the life-cycle of the plant, excluding those which will not be useful for comparison purposes. The reader should bear in mind that the various models covered by the literature have their own specific indicators.

As for the use of these parameters in real models, the authors have detected specific problems that are trying to solve. One of the greatest obstacles is to collect reliable information for estimating the potential values of the proposed indicators. Particularly, inconsistencies and great differences between the data obtained from different sources are very common. On the other hand, 
some concepts or indicators are not clearly defined. Additionally, not all the authors consider the same aspects for a specific indicator. Finally, it is very difficult to find data related to the decommissioning stage. Probably there is a lack of research in this field, and it will be necessary to generate the opportune estimations.

On the other hand, there is variability and uncertainty about the real values that could take some the proposed indicators. Among other issues, the technologies employed in the power plant, its state of conservation and the maintenance strategy can lead to variability and uncertainty about specific environmental, economic and technical indicators. Moreover, there can be disagreement among experts when establishing the weights of the different indicators. Additionally, some experts consider that specific indicators should be evaluated considering non-linearity in the assessment. These three problems will be solved employing a probabilistic simulation method based on the use value functions (MIVES - Monte Carlo method) [6].

\section{References}

[1] D. Meadows, D. Meadows and J. Randers, Limits to Growth: The 30-Year Update, Chelsea Green Publishing, Vermont (2004).

[2] United Nations Organization, Rio Declaration on Environment and Development. United Nations Conference on Environment and Development (UNCED), Río de Janeiro, Brasil (1992).

[3] F. Begic and N.H. Afgan, "Sustainability assessment tool for the decision making in selection of energy system-Bosnian case", in Energy 2007, Vol. 32(10), pp. 1979-1985.

[4] C. Kahraman, I. Kaya and S. Cebi, "A comparative analysis for multiattribute selection among renewable energy alternatives using fuzzy axiomatic design and fuzzy analytic hierarchy process", in Energy 2009, Vol. 34(10), pp. 1603 1616.

[5] M. Dombi, I. Kuti and P. Balogh, "Sustainability assessment of renewable power and heat generation technologies", in Energy Policy 2014, Vol. 67, pp. 264-271.

[6] M.P. de la Cruz, A. Castro, A. del Caño, D. Gómez, M. Lara and J.J. Cartelle, Comprehensive methods for dealing with uncertainty in assessing sustainability. Part I: the MIVES Monte Carlo method, in M.S. García-Cascales, J.M. SánchezLozano, A.D. Masegosa, C. Cruz-Corona editors. Soft Computing Applications for Renewable Energy and Energy Efficiency. IGI-Global, USA (in press; to be published in November 2014).

[7] N.H. Afgan and M.G. Carvalho, "Multi-criteria assessment of new and renewable energy power plants", in Energy 2002, Vol. 27(8), pp. 739-755.

[8] N.H. Afgan, M.G. Carvalho and M. Jovanovic, "Biomassfired power plant: The sustainability option", in International Journal of Sustainable Energy 2007, Vol. 26(4), pp. 179-193.

[9] K. Kowalski, S. Stagl, R. Madlener and I. Omann, "Sustainable energy futures: Methodological challenges in combining scenarios and participatory multi-criteria analysis", in European Journal of Operational Research 2009, Vol. 197(3), pp. 1063-1074.

[10] T. Kaya and C. Kahraman, "Multicriteria renewable energy planning using an integrated fuzzy VIKOR \& AHP methodology: The case of Istanbul", in Energy 2010, Vol. 35(6), pp. 2517-2527.

[11] Instituto para la Diversificación y Ahorro de la Energía Impactos ambientales de la producción eléctrica. Análisis de
Ciclo de Vida de ocho tecnologías de generación eléctrica, Instituto para la Diversificación y Ahorro de la Energía, Madrid (2000) [in Spanish]

[12] G. Assefa and B. Frostell, "Social sustainability and social acceptance in technology assessment: A case study of energy technologies" in Technology in Society 2007, Vol. 29(1), pp. 63-78

[13] R.A.F. de Groot, V.G. van der Veen and A.B. Sebitosi, "Comparing solar PV (photovoltaic) with coal-fired electricity production in the centralized network of South Africa", in Energy 2013, Vol. 55, pp. 823-837.

[14] Instituto para la Diversificación y Ahorro de la Energía, Plan de Energías Renovables (PER) 2011-2020 [Internet], Instituto para la Diversificación y Ahorro de la Energía, Madrid (2011). [In Spanish].

[15] H.Ch. Doukas, B.M. Andreas and J.E. Psarras, "Multicriteria decision aid for the formulation of sustainable technological energy priorities using linguistic variables" in European Journal of Operational Research 2007, Vol. 182(2), pp. 844-855

[16] R.E. Löfstedt, "Public perceptions towards various energy sources in Sweden", in Energy 1991, Vol. 16(7), pp. 10591065.

[17] W. Tang, Z. Li, M. Qiang, S. Wang and Y. Lu, "Risk management of hydropower development in China", in Energy 2013 Vol. 60, pp. 316-324.

[18] K. Molnarova, P. Sklenicka, J. Stiborek, K. Svobodova, M Salek and E. Brabec, "Visual preferences for wind turbines: Location, numbers and respondent characteristics", in Appl Energy 2012, Vol. 92, pp. 269-278.

[19] R.P.J.M. Raven, R.M. Mourik, C.F.J. Feenstra and E. Heiskanen, "Modulating societal acceptance in new energy projects: Towards a toolkit methodology for project managers" in Energy 2009, Vol. 34(5), pp. 564-574.

[20] J.K. Kaldellis, "Social attitude towards wind energy applications in Greece", in Energy Policy 2005, Vol. 33(5), pp. 595-602.

[21] J. Trüby and M. Paulus, "Market structure scenarios in international steam coal trade", in Energy J 2012, Vol. 33(3), pp. 91-123.

[22] W. Li, F. Fu, L. Ma, P. Liu, Z. Li and Y. Dai, "A processbased model for estimating the well-to-tank cost of gasoline and diesel in China", in Appl Energy 2013, Vol. 102, pp. 718-725.

[23] Y. Liu, X. Wang, Y. Xiong, H. Tan and Y. Niu, "Study of briquetted biomass co-firing mode in power plant", in Appl Therm Eng 2014, Vol. 63(1), pp. 266-271.

[24] M. Yildirim and K. Erkan, "Determination of acceptable operating cost level of nuclear energy for Turkey's power system", in Energy 2007, Vol. 32(2), pp. 128-136.

[25] A. Ahmad and M.V. Ramana, "Too costly to matter: Economics of nuclear power for Saudi Arabia", in Energy 2014, Vol. 69, pp. 682-694.

[26] K. Zweibel, "Should solar photovoltaics be deployed sooner because of long operating life at low, predictable cost?", in Energy Policy 2010, Vol. 38(11), pp. 7519-7530.

[27] F. Ueckerdt, L. Hirth, G. Luderer and O. Edenhofer, "System LCOE: What are the costs of variable renewables?", in Energy 2013, Vol. 63, pp. 61-75.

[28] Nuclear Energy Agency, Decommissioning nuclear power plants. Policies, strategies and costs [Internet], Organisation for Economic Co-operation and Development, Paris (2003).

[29] N.I. Sinisuka and H. Nugraha, "Life cycle cost analysis on the operation of power generation", in Journal of Quality in Maintenance Engineering 2013, Vol. 19, pp. 5-24.

[30] D. Diakoulaki and F. Karangelis, "Multi-criteria decision analysis and cost-benefit analysis of alternative scenarios for the power generation sector in Greece", in Renewable and Sustainable Energy Reviews 2007, Vol. 11(4), pp. 716727. 